\title{
COMMUNICATIONS
}

\section{RADIOTHERAPY OF NON-MALIGNANT DISEASES OF THE EYE*}

\author{
BY \\ M. LEDERMAN \\ From the Radiotherapy Department, Royal Marsden Hospital, and \\ Moorfields, Westminster and Central Eye Hospital
}

RADIOTHERAPY has been used in the treatment of non-malignant disease of the eye for over 50 years; but progress in the development of this form of treatment has been hampered by its alleged dangers to the eye. It is true that in the early days ocular damage was frequently encountered, but the traditional view that the eye is readily damaged by radiation, was based upon early unsound experimental work, and the memory of the clinical disasters encountered by the pioneers. To-day this view can no longer be maintained, for with reasonable technical care and proficiency the radiation treatment of non-malignant disease of the eye should entail no risk of ocular damage either as a complication or as a sequela.

\section{PURPOSE OF RADIOTHERAPY}

In assessing the value of and indications for radiotherapy in non-malignant diseases of the eye, the purpose or object of this form of treatment must be clearly appreciated; otherwise the treatment may be misapplied, so that the patient is not benefited and the method itself becomes discredited.

(A) Non-NeOPlastic Disease.-In such cases the main aims of radiation treatment are:

(1) To relieve symptoms, particularly pain.

(2) To promote healing by assisting:
(i) the resolution of inflammatory processes;
(ii) the absorption of a haematoma or haemorrhage;
(iii) the epithelization of an ulcerated surface;
(iv) the organization and removal of granulation tissue.

(3) To affect blood vessels:

(i) to reduce vascular engorgement and congestion accompanying inflammation;

(ii) to obliterate or reduce in size newly-formed vessels invading the cornea.

(4) To reduce intra-ocular tension. 
(5) To restore function. E.g. an attempt may be made to improve vision where the cornea is the seat of an opacity, dystrophy, or degenerative process.

(B) Non-malignant Tumours. - In such cases radiation can be employed for the following purposes:

(1) To destroy a tumour for cosmetic reasons.

(2) To destroy or hasten the natural resolution of a tumour adjacent to and endangering the eye.

(3) To eradicate a precancerous condition.

The precise mode of action whereby radiation can favourably influence an inflammatory process is not known, but there are three possible mechanisms which may separately or together play some part in producing a favourable response (Pohle, 1950):

(1) A possible stimulation of antibodies.

(2) An effect on the cellular elements of the exudate, particularly the leucocytes.

(3) An effect upon the blood vasculature, especially the capillaries.

In the case of the benign tumours, the mode of action of radiation is by selective destruction of the tumour tissue, and it presumably differs in no fundamental way from the mode of action of radiation on other neoplastic processes.

\section{INDICATIONS AND SELECTION OF CASES FOR RADIOTHERAPY}

\section{(A) INFLAMMATORY AND OTHER NON-NEOPlastic CONDITIONS}

Whilst the exact mode of action of radiation in these conditions is uncertain and further speculation on this topic would be profitless, the fact remains that a sound knowledge of the clinical effects of radiotherapy and the purposes to which these can be put, provide a reasonable basis for selecting cases for this form of treatment. Table I (opposite) lists the nonneoplastic lesions, in the treatment of which experience shows radiotherapy to be of value.

It is obvious that only a minority of patients suffering from these diseases is likely to require radiotherapy, and an indiscriminate resort to this form of treatment is to be deprecated. Radiation is, after all, a noxious agent, its precise mode of action is still a matter for conjecture, and its effects are neither prompt nor certain. In these circumstances, any other methods of treatment known to give satisfactory results should always be given priority.

Whilst a hasty resort to radiotherapy is not to be recommended, undue tardiness is equally to be avoided. A patient failing to respond to recognized therapeutic measures within a reasonable time should not be deprived of possible help from radiotherapy, nor should he be left until the disease progresses to the stage when radiotherapy can only give symptomatic relief. 
TABLE I

NON-NEOPLASTIC LESIONS

\begin{tabular}{|c|c|c|}
\hline \multirow{5}{*}{$\begin{array}{l}\text { Inflammatory } \\
\text { Processes }\end{array}$} & Pyogenic & Blepharitis \\
\hline & Granulomatous & $\begin{array}{l}\text { Tuberculosis } \\
\text { Sarcoidosis }\end{array}$ \\
\hline & Allergic & $\begin{array}{l}\text { Vernal catarrh } \\
\text { Phlyctenular kerato-conjunctivitis }\end{array}$ \\
\hline & Viral & $\begin{array}{l}\text { Superficial punctate keratitis } \\
\text { Post-herpetic pain } \\
\text { Dendritic ulcer } \\
\text { Disciform keratitis } \\
\text { Trachoma }\end{array}$ \\
\hline & Unknown aetiology & $\begin{array}{l}\text { Rosacea keratitis } \\
\text { Marginal ulcerative keratitis }\end{array}$ \\
\hline \multirow{4}{*}{ Miscellaneous } & Corneal lesions & $\begin{array}{l}\text { Ulcers (including Mooren's) } \\
\text { Opacities following infection or trauma } \\
\text { Dystrophies and degenerations (including pterygium) } \\
\text { Traumatic lesions and recurrent erosions }\end{array}$ \\
\hline & \multicolumn{2}{|l|}{ Epithelial downgrowths } \\
\hline & Vascular abnormalities & $\begin{array}{l}\text { Corneal vascularization (particularly after grafting) } \\
\text { Eales's disease } \\
\text { Retinal haemorrhage } \\
\text { Venous thrombosis }\end{array}$ \\
\hline & $\begin{array}{l}\text { Raised intra-ocular } \\
\text { tension }\end{array}$ & Secondary glaucoma \\
\hline
\end{tabular}

Radiotherapy should therefore be considered in the following circumstances:

(1) Where there is no response to recognized therapeutic methods within a reasonable time (1 to 2 months).

(2) Where no accepted method of treatment exists and there is reason to believe that radiotherapy may be of help.

(3) For chronic progressive lesions accompanied by symptoms which radiotherapy may relieve without necessarily arresting the course of the disease.

(4) For chronic relapsing lesions wherein periods of apparent improvement or healing are followed by repeated recurrence.

Of the conditions listed in Table I, the following are of most importance and interest to the radiotherapist:

(1) Mooren's ulcer.

(2) Rosacea keratitis.

(3) Corneal vascularization.

(4) Virus infections.

(5) Vernal catarrh.

(6) Pterygium. 
(1) In cases of Mooren's ulcer, radiotherapy is the only method of treatment known to be of value (Fig. 1).

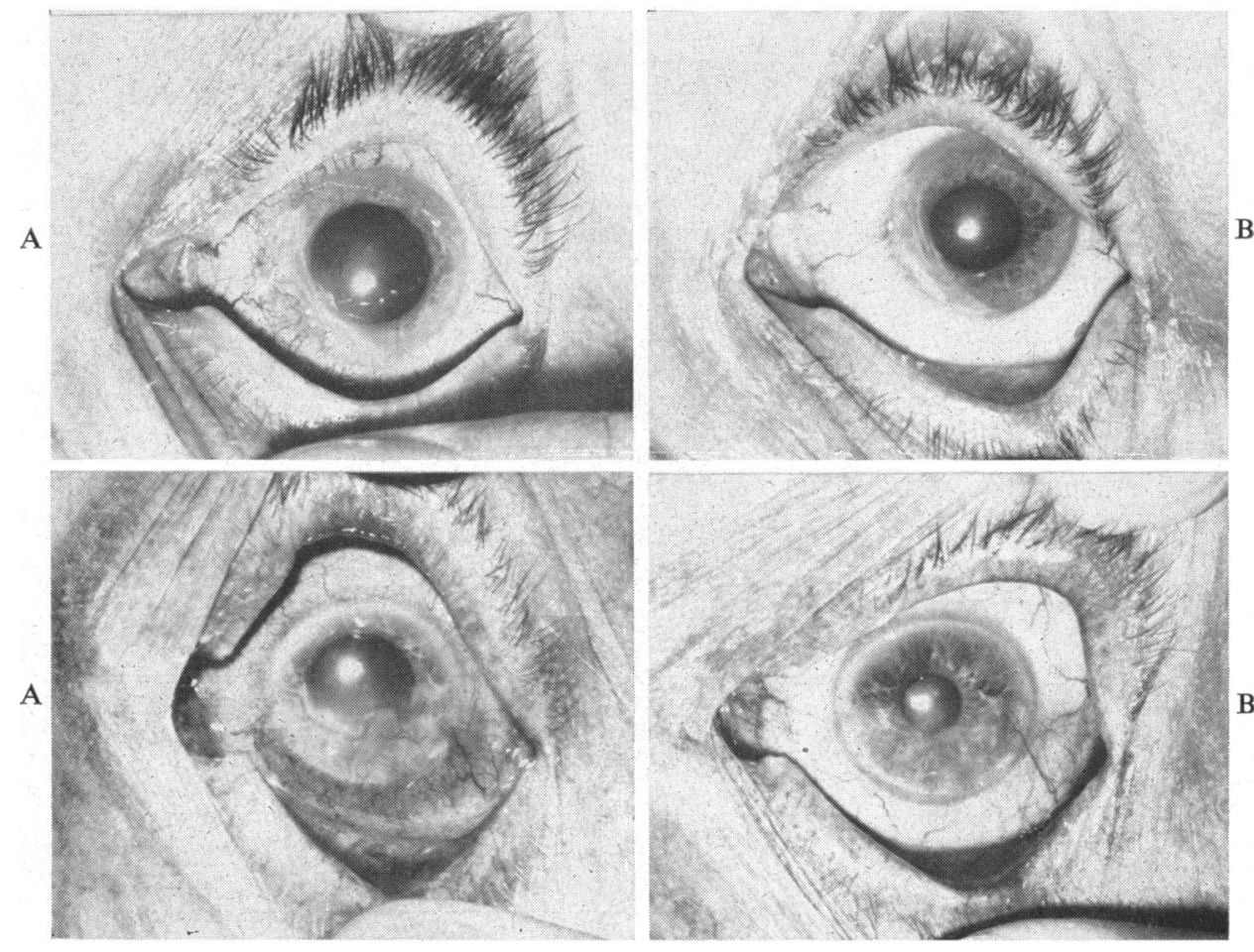

FIG. 1.-Mooren's ulcer in two patients.

A. Before radiation treatment. B. After radiation treatment.

(By courtesy of the Editors of the British Journal of Radiology.)

(2) There are very few remedies that can compare with radiotherapy in the treatment of rosacea keratitis, where radiation virtually proves itself the "morphia of the eye" (Fig. 2, opposite).

These two lesions are the sole exceptions to the general rule that radiotherapy should be used only as a last resort in the treatment of non-neoplastic processes. The early use of radiotherapy in Mooren's ulceration gives the patient his only chance of cure; in the treatment of rosacea keratitis, it gives the patient his best chance of avoiding loss of vision through the scarring that follows repeated attacks.

(3) The judicious use of radiation for corneal vascularization associated with keratoplasty can go far to help obtain a satisfactory functional result as in Fig. 3 (opposite) and Figs 4 and 5 (overleaf).

(4) In virus infections (Fig. 6, overleaf), and superficial punctate keratitis (Fig. 7, overleaf), radiotherapy is only occasionally curative, but it can nevertheless effect a certain degree of symptomatic relief not to be obtained by other remedies (Lederman, 1956b). 

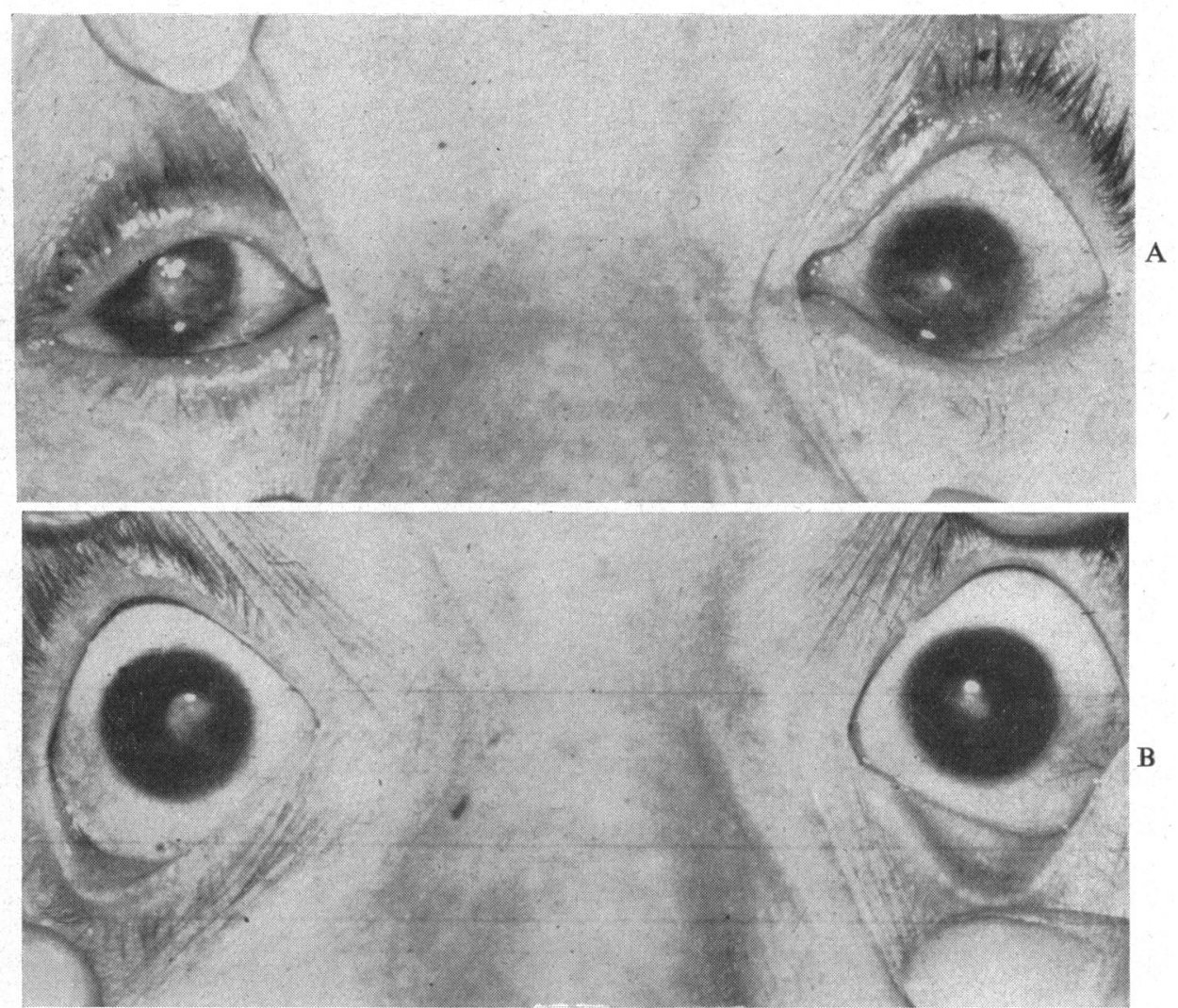

FIG. 2.-Rosacea keratitis.

$\begin{array}{ll}\text { A. Before radiation treatment. } & \text { B. After radiation treatment. }\end{array}$

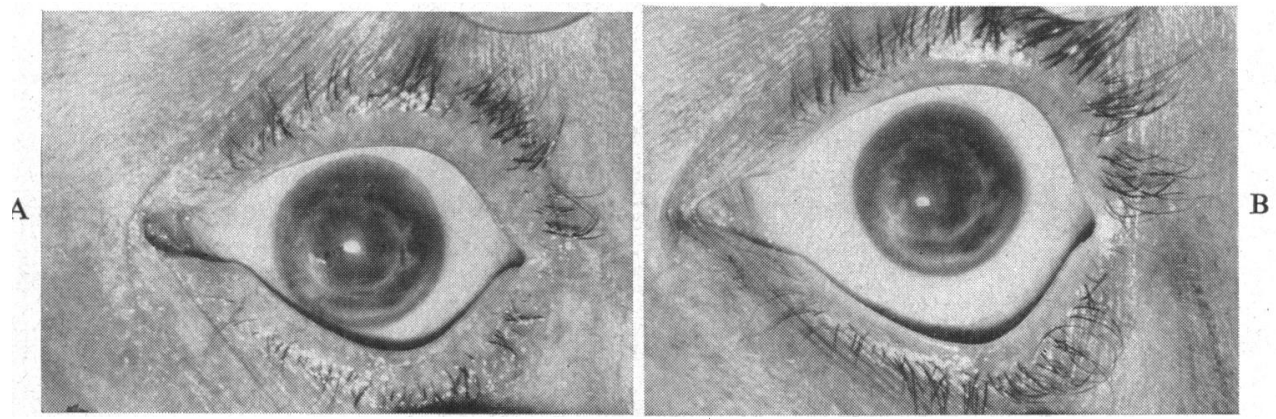

Fig. 3.-Lamellar graft.

A. Before radiation treatment. B. After radiation treatment.

(By courtesy of the Editors of the British Journal of Radiology.)

(5) A note of warning must be sounded in relation to the radiation treatment of vernal catarrh. It has been known for a very long time that radiotherapy can help sufferers from this condition, but in recent years there has been an enthusiastic revival of the beta-ray treatment of this' disease, particularly in the United States. Although the sufferers are usually 

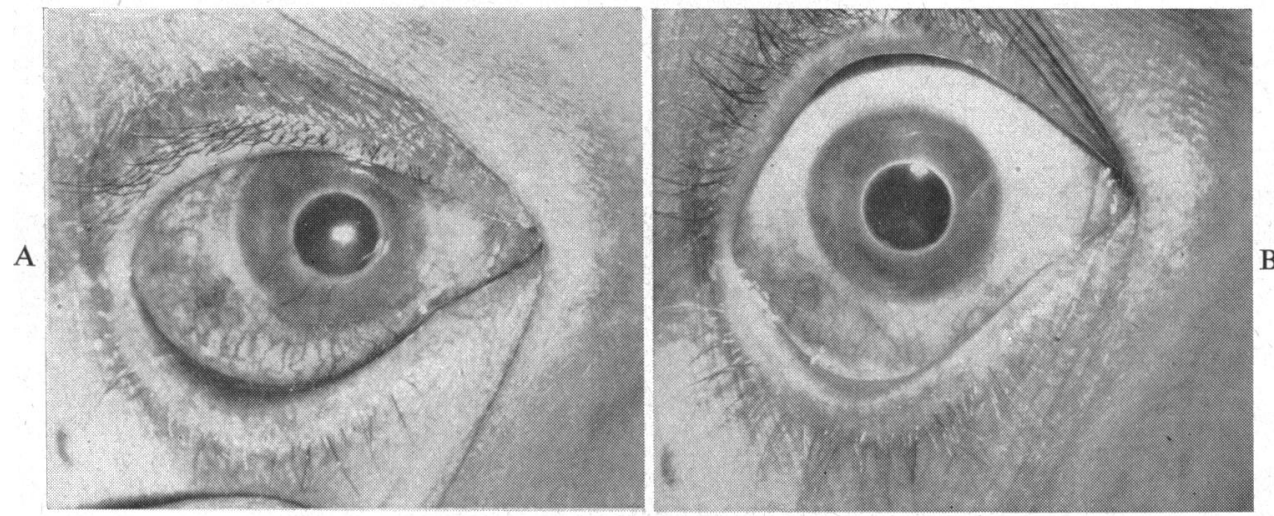

FIG. 4.-Full-thickness corneal graft.

A. Before radiation treatment. B. After radiation treatment.

(By courtesy of the Editors of the British Journal of Radiology.)
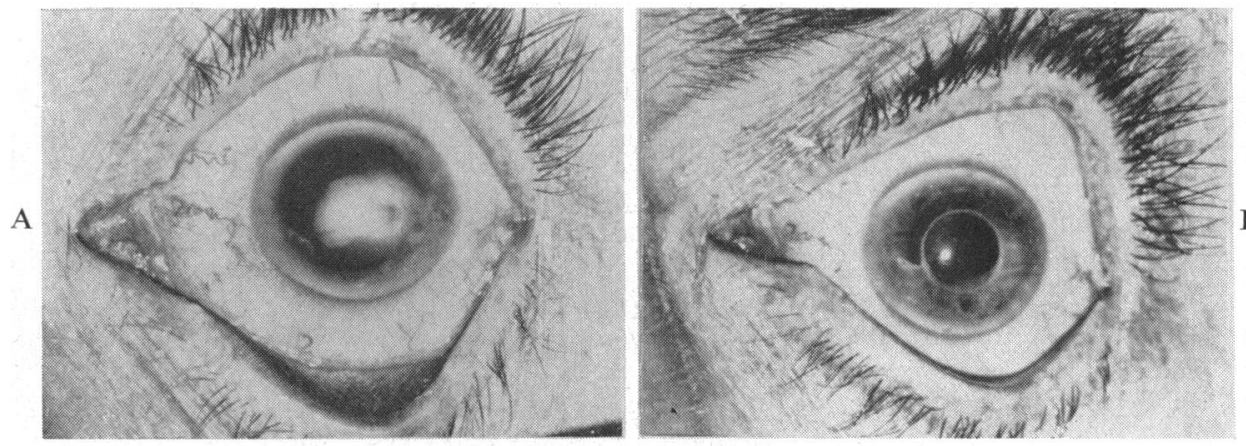

Fig. 5.A.-Disciform keratitis.

B. Full-thickness graft in association with pre- and post-operative irradiation.

children and the disease is seasonal and ultimately self-limiting, high doses of beta-radiation have been recommended as a method of eradicating the characteristic "cobble-stone" papules that appear on the tarsal conjunctiva. To any radiotherapist conversant with the effects of beta-radiation, the consequences of high doses applied to the mucosal surfaces of the lids could easily be predicted-namely, replacement fibrosis with atrophy and scarring of the palpebral conjunctival mucous membrane. Merriam (1956) has pointed out the risks of irradiating vernal catarrh in a recent paper on the effects on the eye of beta-radiation. He gives the following graphic account of the state of the unfortunate sufferers from this disease who have been misguidedly submitted to over-enthusiastic beta-irradiation:

When the roughened keratinized surface (of the lid) rubs over the cornea, it produces a punctate keratitis with severe photophobia, lacrimation, and blepharospasm. This persists throughout the patient's lifetime, is resistant to treatment, and in our experience has been found to be much more debilitating than the disease originally treated. This possible effect should be given serious consideration before irradiation is advocated for a condition in which 90 per cent. of the cases subside spontaneously with local medication. 

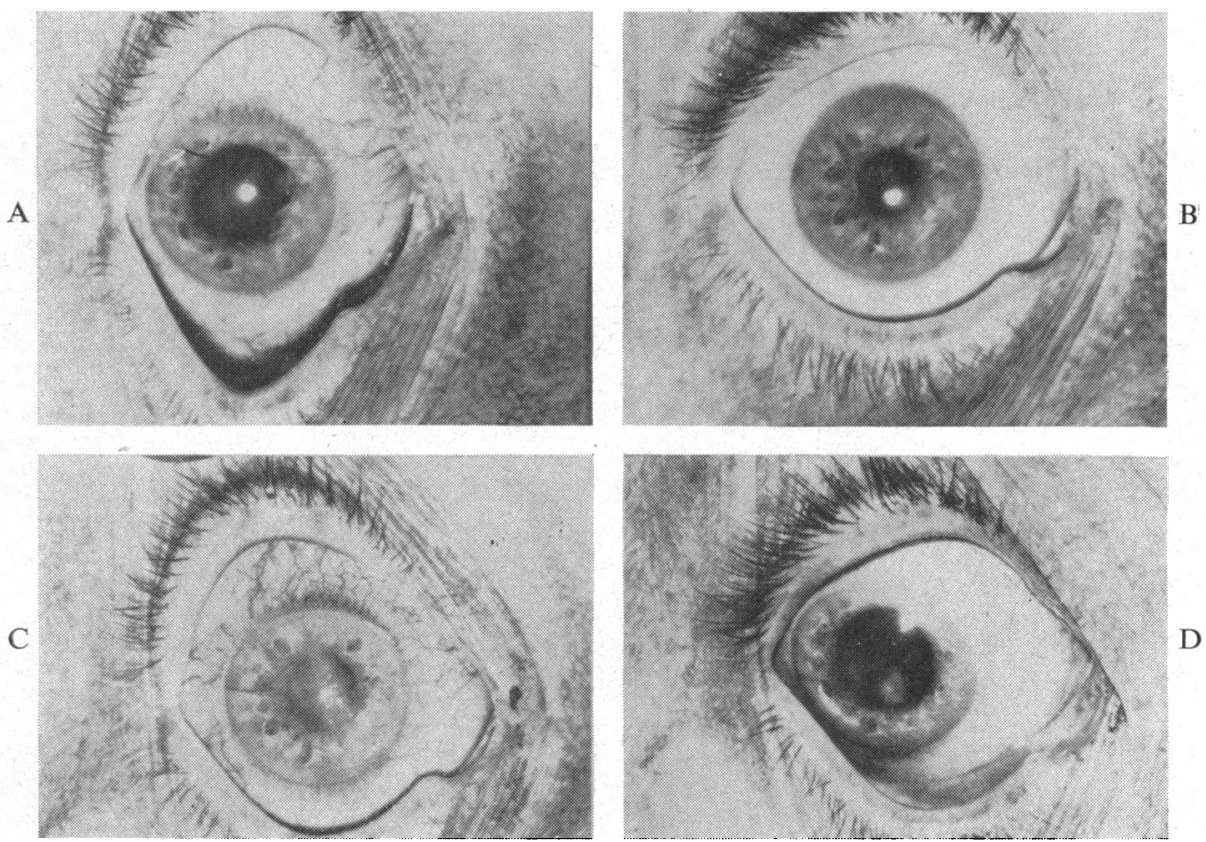

FIG. 6.-Dendritic ulcer. Second attack 5 years later.

A. Before treatment.
C. Before treatment.

B. After beta-radiation.

D. After beta-radiation.
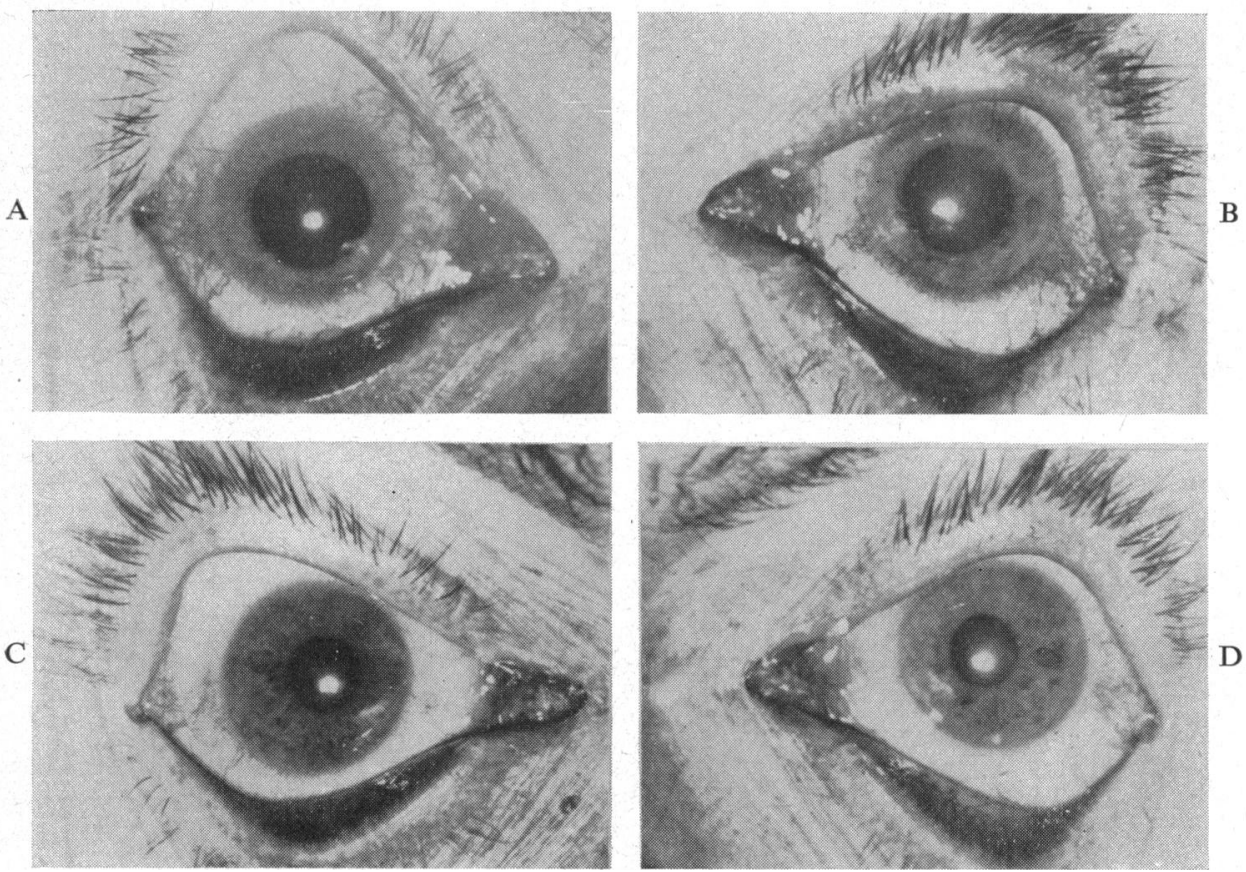

FIG. 7.-Bilateral superficial punctate keratitis.

$A$ and B. Before treatment.

C and D. After small doses of $x$-ray therapy. 
The present writer has not practised the beta-ray treatment of vernal catarrh using high doses; after tentative trials, when it became obvious that the papules could not be eradicated with small safe doses, beta-radiation was virtually abandoned and small doses of $x$-radiation were used instead. The aim of treatment has been either prevention by irradiation one month before the expected onset of the seasonal attack, or reduction of the acuteness of the florid attack to relieve symptoms until the seasonal respite occurs. Beta-radiation is indicated only in the rare cases in which the bulbar conjunctiva is affected (Figs 8, 9, and 10).
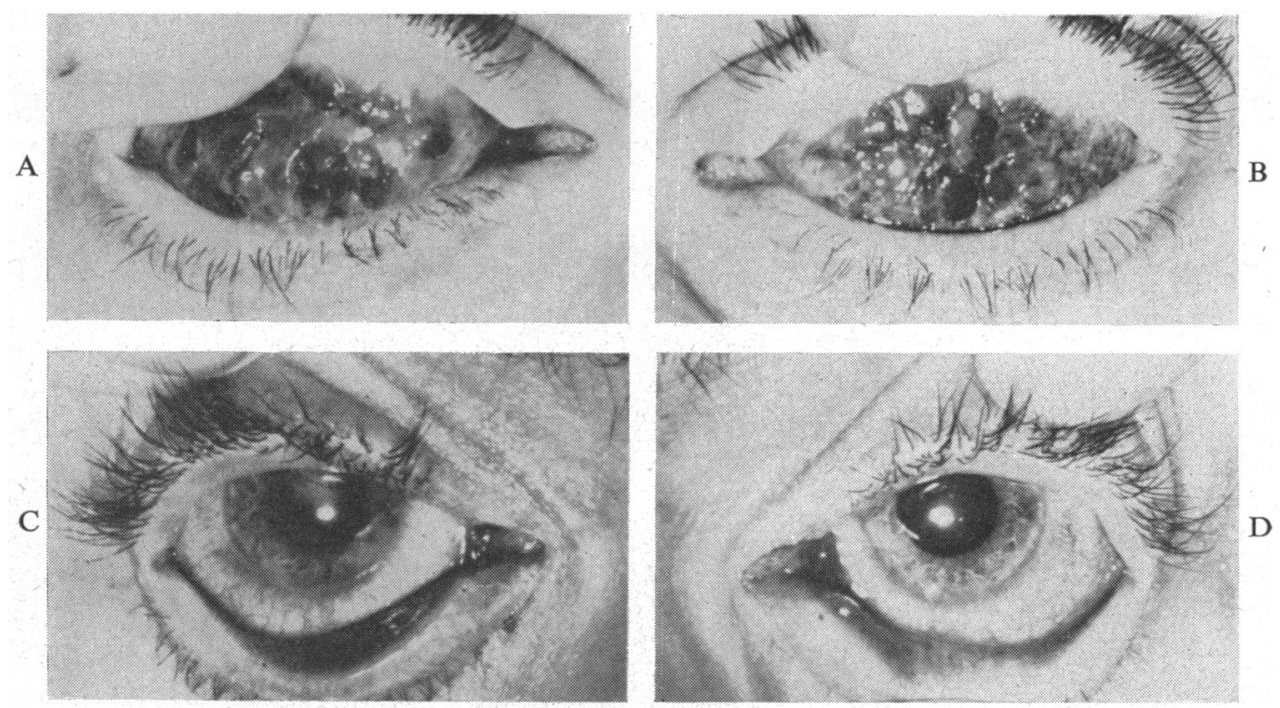

Fig. 8.-Vernal catarrh.

A and B. Typical "cobble-stone" appearance of lids

$\mathrm{C}$ and D. Associated corneal ulceration.

(6) Most of the cases of pterygium seen by the writer have been in patients coming from tropical and subtropical countries. The customary treatment is surgical removal, but the recurrence rate is by no means negligible. Radiotherapy should be reserved for the recurrent case, when excision and immediate post-operative radiation is the treatment of choice (Fig. 11, overleaf).

(B) Benign Tumours

The non-malignant tumours of the outer eye for which radiotherapy may be indicated are haemangiomata, papillomata, hyperkeratoses, and keloids. The need for and value of radiotherapy varies for each lesion.

(1) Haemangiomata. - It is probably true that most haemangiomata occurring in infancy disappear spontaneously without treatment. In spite of this, however, there are certain medical indications for active treatment:

(i) Presence of haemorrhage or infection. 

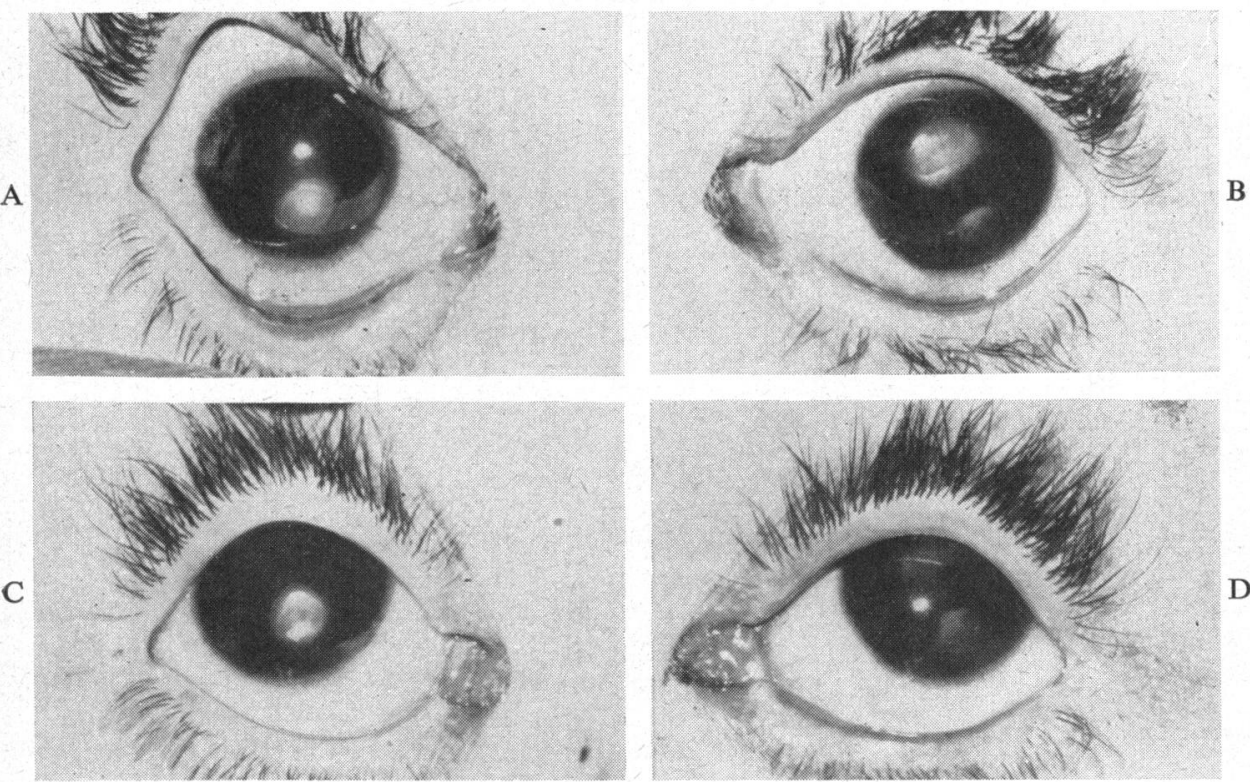

Fig. 9.--Vernal Catarrh

A and B. State of eyes before small doses of $x$-ray therapy-corneal damage is present.

C and D. State of eyes after treatment-the eyes are white and quiet and there has been relief of symptoms.

A
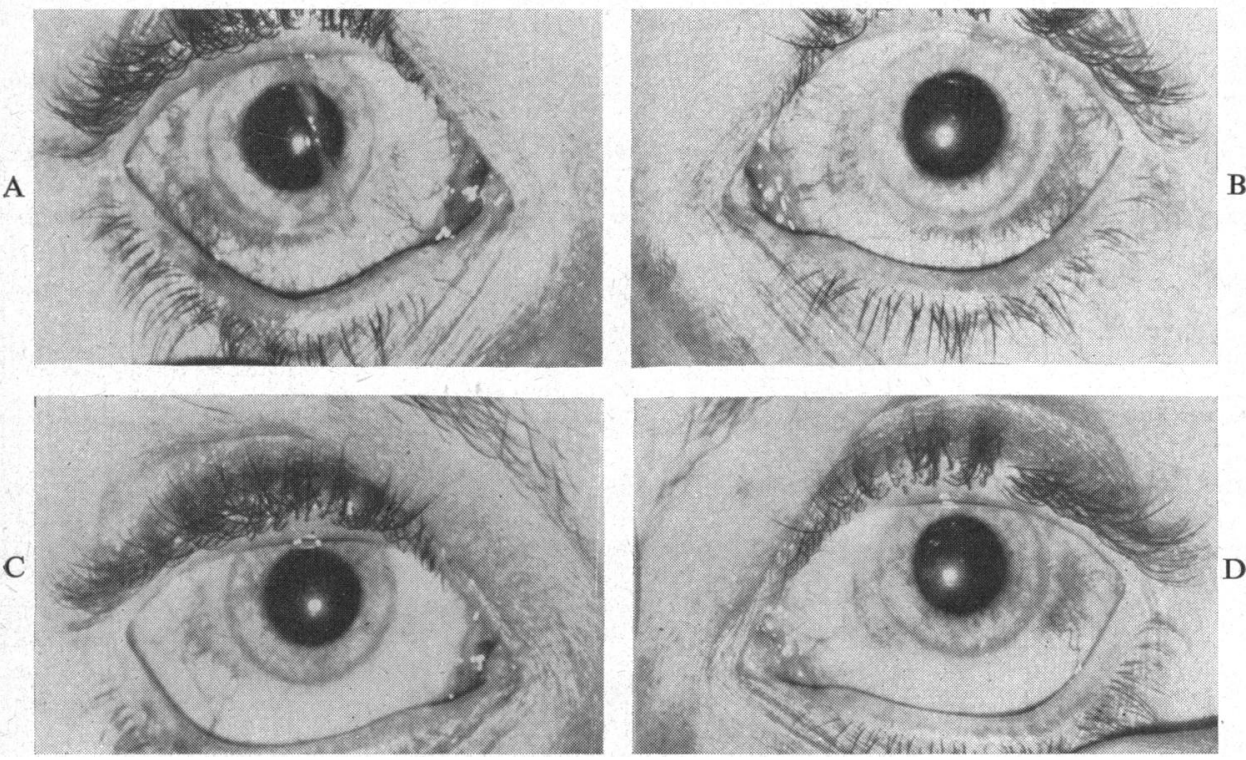

Fig. 10.-Bilateral vernal catarrh.

A and B. Bilateral bulbar vernal catarrh before treatment.

C and D. After beta-radiation-symptomatically improved. 

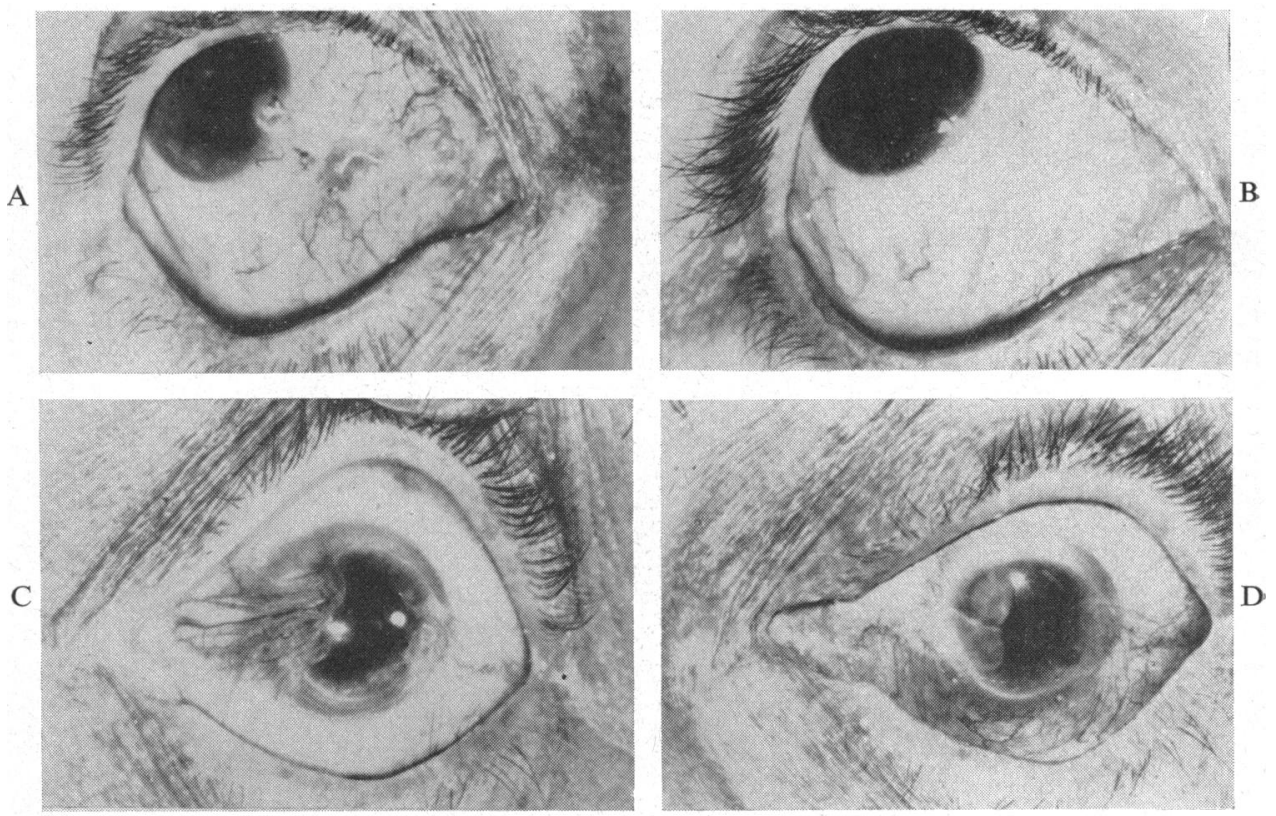

Fig. 11.-Recurrent pterygia.

A. Before treatment.

B. After treatment.

Treatment was by surgery and immediate post-operative beta-radiation.

(ii) Situation of the haemangioma in a region exposed to frequent trauma, i.e. the scalp or the napkin area, or where its presence predisposes to infection of a neighbouring organ; e.g. infection may take place in the conjunctival sac where the lids are closed by an angioma.

In addition to these medical indications there is one further important indication; namely, the child is treated for the mother's sake. Many of the sufferers are first-born girl babies, and it is unreasonable to expect the mother to accept verbal reassurance that all will be well, particularly during the period when the angioma apparently increases in size with the growth of the infant. Radiotherapy is the treatment of choice for lid angiomata. There is no indication in these cases for excisional surgery which can only result in unnecessary mutilation and should be avoided at all costs. Radiotherapy offers a simple and safe remedy, the judicious use of which can arrest the growth of the angioma and restore confidence and peace of mind to the parents (Figs 12, 13, and 14, opposite).

(2) Papillomata.-The treatment of choice for either the true papilloma, or the infective wart is surgical removal. Such warts may be single or multiple and may affect the lids or the conjunctiva. It is rarely possible to cause true papillomata to disappear by using small safe doses of radiation, and an adequately effective dose of radiation must inevitably be accompanied 


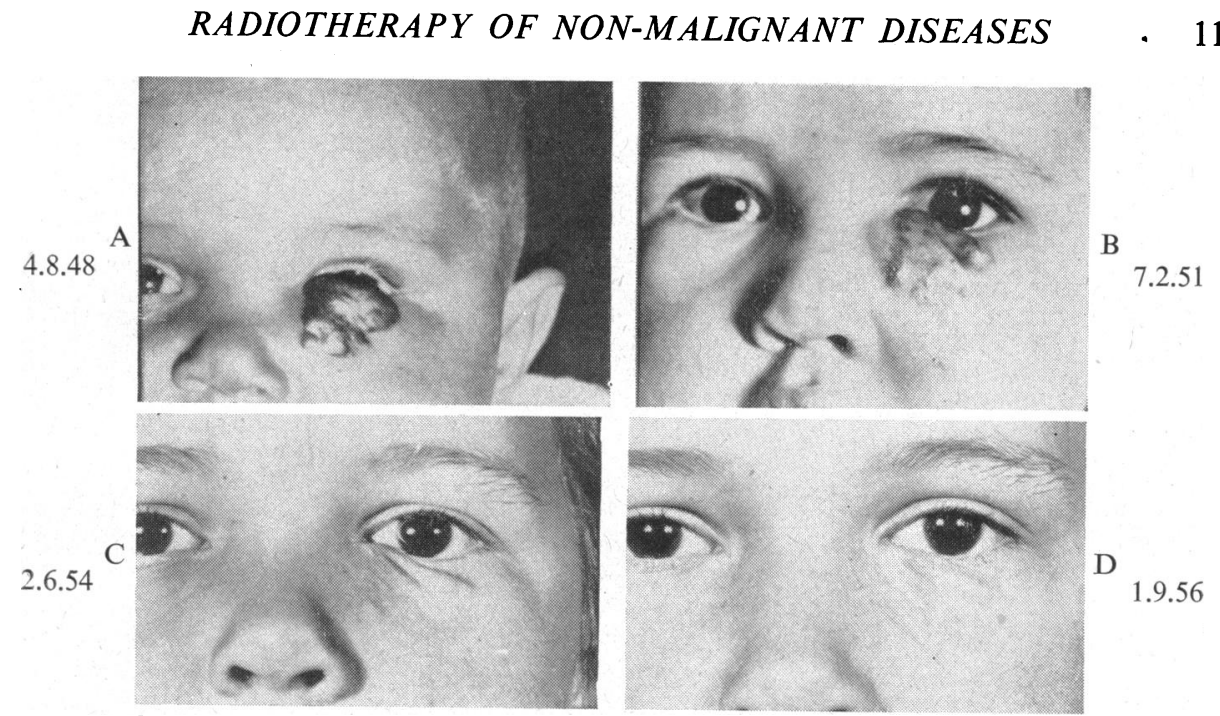

Fig. 12.- Haemangioma of lower lid treated by radium applicator showing rate of regression.

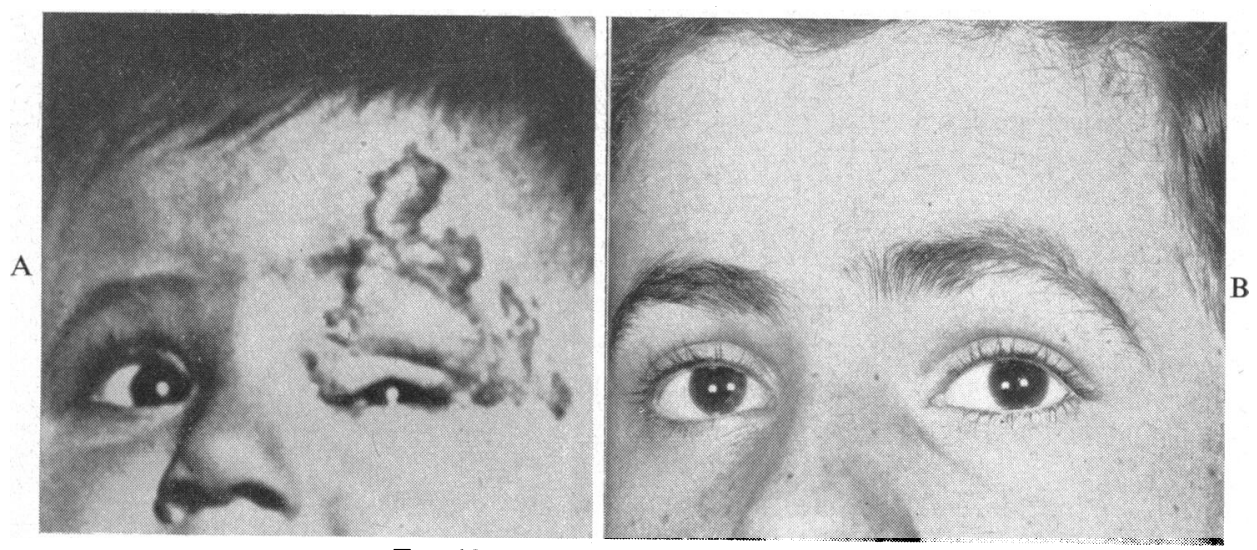

Fig. 13.-Haemangioma of upper lid.

$\begin{array}{ll}\text { A. Before radium treatment. } & \text { B. } 10 \text { years later. }\end{array}$

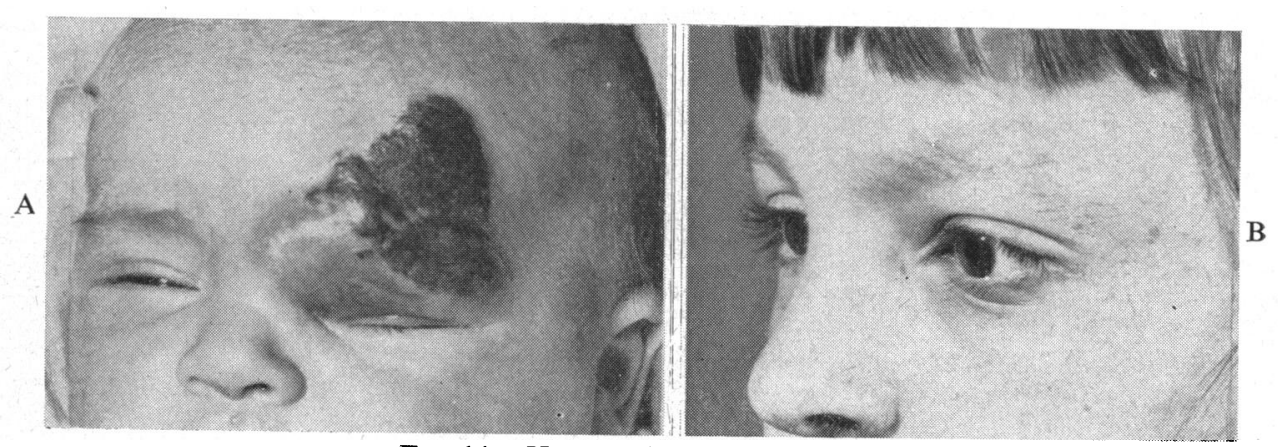

Fig. 14.-Haemangioma of upper lid.

$\begin{array}{ll}\text { A. Before radium treatment. } & \text { B. } 10 \text { years later. }\end{array}$ 
by a local tissue reaction. Such reactions occurring in regions away from the eye are reasonably free from risk, but in the eyelid or on the conjunctiva there are three special complications, the risk of which is real enough to contraindicate radiotherapy:

(i) Keratinization of the conjunctival epithelium of the treatment area. This occurs rarely but when it does it can be a serious matter, since, apart from producing an irritable eye, it may also damage the cornea (Fig. 15).
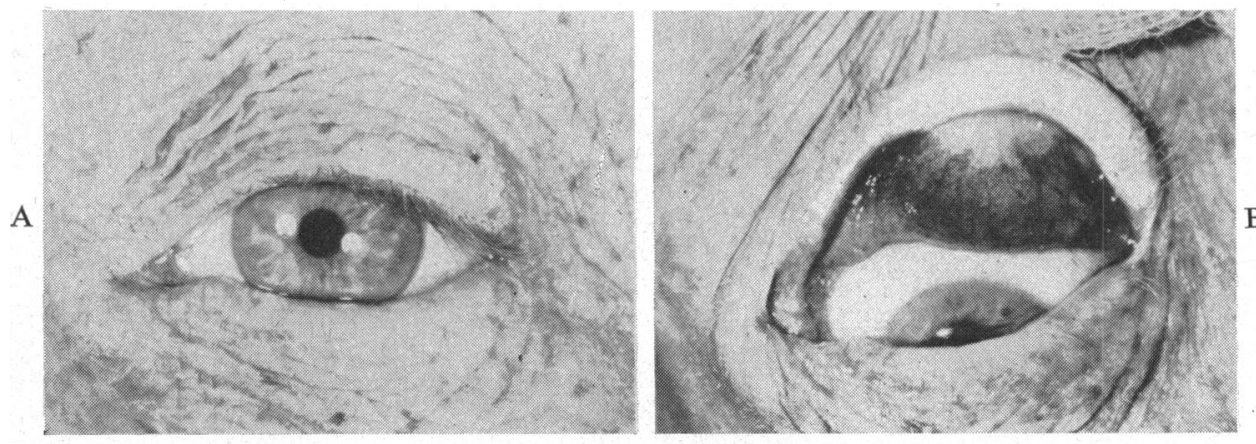

Fig. 15.-Papilloma of upper lid.

A. Before treatment. B. After treatment. The lesion has gone but there is keratinization of the lid conjunctiva in the treated area.

(ii) In the writer's experience a single-dose technique (2,000 r by L.V.T. $60 \mathrm{kV}$.) tends to produce a higher necrosis rate than fractionated techniques. The reason for using these single-dose techniques is their simplicity and economy, but radio-necrosis is a high price for a patient to pay for the treatment of a non-malignant lesion for which a safe surgical alternative is available.

(iii) The $x$-ray treatment of an epibulbar wart, particularly if situated near the limbus, may be followed by a radiation cataract. This risk can be minimized by the use of beta-radiation.

In spite of the desire to use surgery whenever possible, there are certain indications for radiotherapy in the treatment of papillomata:

(i) For a solitary sessile papilloma affecting more than one-third of the lid margin, when surgery would involve plastic repair of the lid (Fig. 15).

(ii) Multiple papillomata of the lids and conjunctiva (Figs 16 and 17, opposite).

(iii) Repeated recurrences after surgery.

(3) Keratoses.-The senile type of keratosis is usually a precancerous lesion and when affecting the lid margin is best treated by radiotherapy, because a wider area of tissue can be irradiated than can be excised. The need to irradiate or excise a wide area of tissue surrounding the lesion is due to the presumed "instability" of the tissues from which the keratosis arises. 

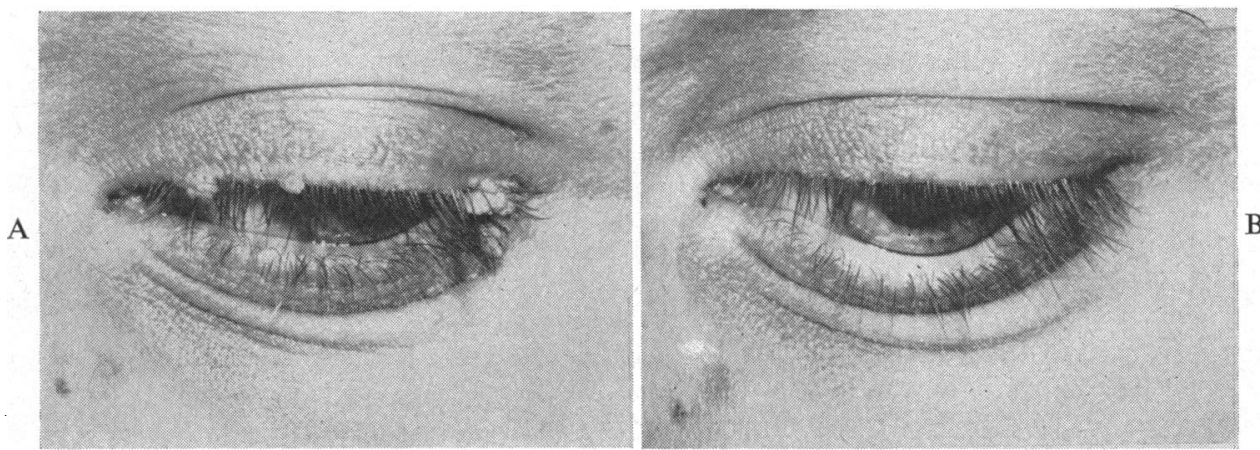

Fig. 16.-Multiple papillomata of the lids and bulbar conjunctiva treated by a combination of low-voltage $x$-rays to lid and beta-radiation to the bulbar conjunctiva.

A. Before treatment.

B. After treatment.
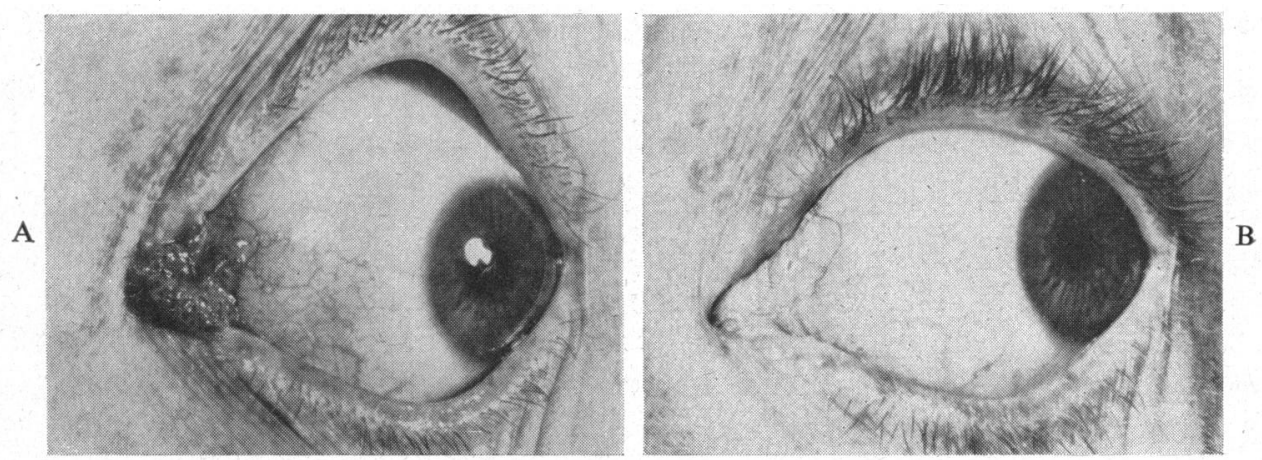

Fig. 17.-Papilloma of the conjunctiva.

A. Before radiation treatment. B. After radiation treatment.

(4) Keloids. - These may form in a scar on the lid, or may occur after injury or post-operatively. If the keloid is of the raised, red, fleshy type, radiotherapy should be undertaken, but if the lesion is of the hard, white, linear variety, excision associated with pre- or post-operative irradiation is indicated.

\section{FACtors influencing Choice of TeChNique}

\section{(A) Non-Neoplastic Lesions}

The one factor which must dominate treatment is safety; in no circumstances must risks of damage be taken. Treatment can be made safe by attention to technical detail and utmost care in dosage.

The superficial situation and accessibility of the outer eye considerably simplifies apparatus requirements. With the exception of irradiation of the Gasserian ganglion for post-herpetic pain, which requires high-voltage therapy, all other non-neoplastic lesions can be treated by low-voltage therapy or beta-radiation, used either separately or in combination.

The particular method to be used chiefly depends on the acuteness and the extent of the lesion. 
(1) Low-voltage therapy is always used for an acute or extensive lesion. The radiation is applied directly to the closed eye so that the whole of the outer eye and the eye-ball are irradiated.

(2) Beta-radiation is reserved for chronic lesions, chiefly affecting the cornea. Beta-radiation is not used in the presence of:

(a) severe lid spasm,

(b) a small pupil, marked ciliary congestion, or other evidence of uveal irritation or inflammation.

In the presence of lid spasm, any difficulty in inserting the beta-ray shell into the conjunctival sac may result in injury to the cornea, and the strontium beta-ray dose delivered to any co-existing inflammatory process deep to the cornea might prove excessive and produce an exacerbation of symptoms.

(3) Quite frequently, $x$ - and beta-radiation may be used in combination. Thus, for an acute kerato-conjunctivitis or a deep keratitis associated with an iridocyclitis, treatment can be begun with low-voltage therapy and when the eye is reasonably comfortable and white, beta-rays can be applied to any persistent localized corneal lesion.

The effect desired from the treatment governs the selection of the particular radiation and dosage used. The purpose of the $x$-ray treatment is to assist the resolution of an acute inflammatory process affecting a part or the whole of the eye. The radiation is, therefore, applied in very small doses to the affected organ in its entirety on the assumption that the favourable effect of the radiation mediates through the blood supply, all of which should therefore be exposed to the radiation. In the case of beta-radiation, the "antiinflammatory effect" of radiation is not usually sought, but the purpose is to heal a corneal ulcer or obliterate unwanted blood vessels invading the cornea; to achieve this, the strictly localized effects of high doses of betaradiation are ideal.

There are two standard techniques for treating non-neoplastic lesions of the eye.

(1) X-Radiation: Bulbar or "Whole Eye" Technique.-This is so-called because no attempt is made to protect or shield any part of the globe or lids, treatment being given through a $3-\mathrm{cm}$. diameter circular field placed directly over the closed lids. The apparatus used has the following factors: $45 \mathrm{kV}$., $2 \mathrm{~mA}$.; filter $1 \mathrm{~mm}$. A1; focal-skin distance $4 \mathrm{~cm}$.

The $x$-ray dosage employed in the treatment of an infection of the outer eye is always minimal, namely $10 \mathrm{r}$, and it would appear that, if radiotherapy is going to help, this minute dose is perfectly adequate. In my experience, there is no advantage in giving higher doses as, for example, of $100 \mathrm{r}$ : the results are the same; the smaller dose is absolutely safe, does not provoke exacerbations, requires no manipulation of the lids, and can be continued for more than a month with safety. In the event of a relapse, a course of low-dosage treatment can be repeated two or three times a year. 
$X$-ray treatment is given once or twice a week for 4 weeks, and the treatment can be stopped if the eye is comfortable and quiet at the end of this period. If the eye is white and corneal ulceration persists, beta-radiation can be used; if no improvement is observed, radiation treatment should be abandoned completely.

(2) Beta-Radiation.-This forms the mainstay of the treatment of corneal lesions. The apparatus comprises a plastic shell containing radio-active strontium foil (Lederman, 1956a). The shell is inserted into the conjunctival sac so that the radio-active surface comes into contact with the cornea and the surface of the globe. A range of such shells is available (Figs 18 and 19).

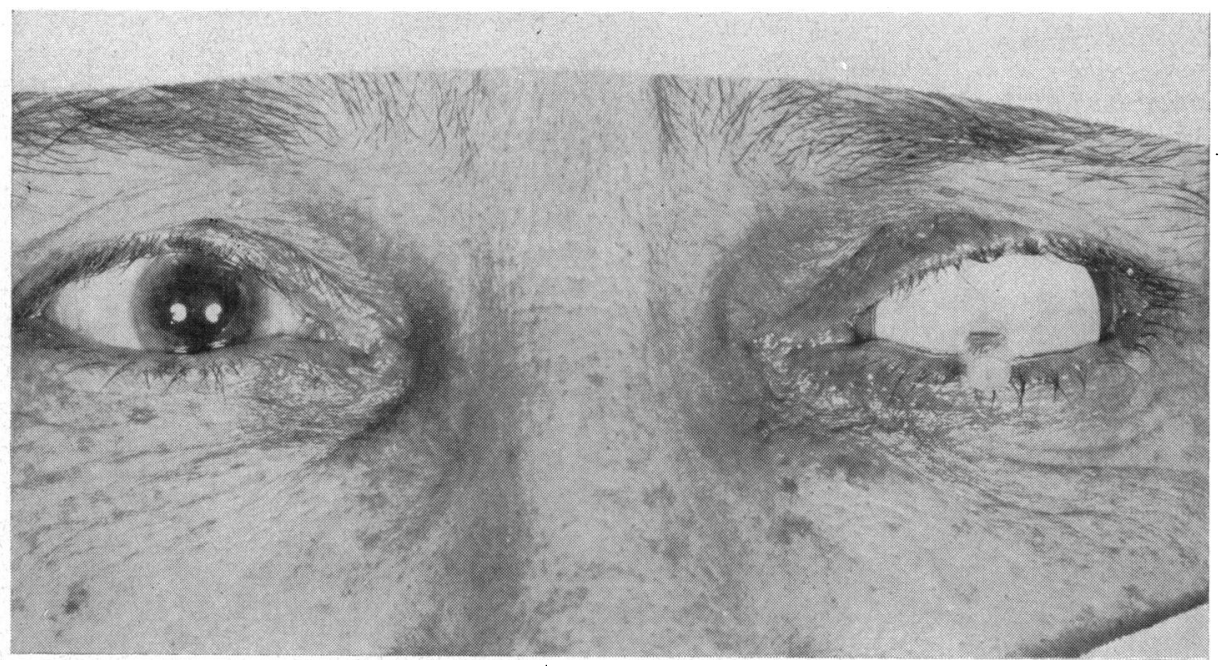

FIG. 18.-Radio-active strontium beta-ray applicator in place in conjunctival sac. (By courtesy of the Editors of the British Journal of Radiology.)

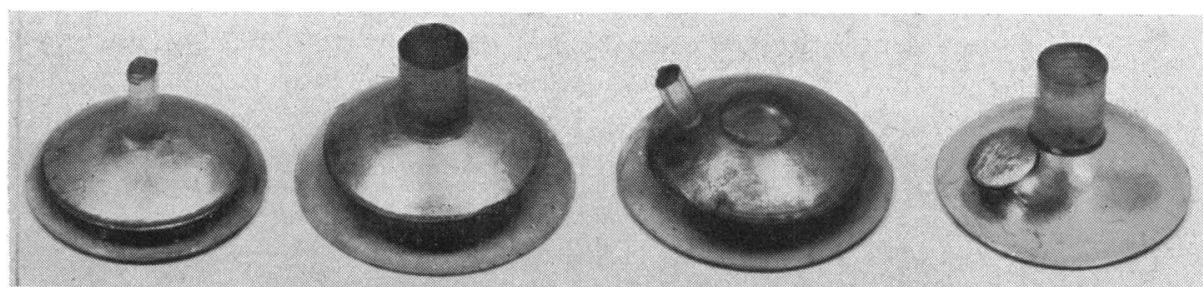

FIG. 19.-Radio-active strontium beta-ray applicators showing range of applicators available. (By courtesy of the Editors of the British Journal of Radiology.)

The dosage required depends on the lesion being treated.

For Mooren's ulcer single doses of 500 to $1,000 \mathrm{r}$ are given at weekly intervals for 4 weeks.

For corneal ulceration of dendritic or rosacea origin a dose of $500 \mathrm{r}$ is given weekly.

For corneal vascularization after grafting treatment may be begun 10 to 14 days after operation, and 500 to 1,000 r are given weekly for 4 weeks. The dose and the type of applicator used depend on the state of the eye when seen, and the extent, 
age, and depth of the vessels to be treated; the treatment is the same whether the graft be lamellar or full-thickness. For pre-operative corneal irradiation, doses of the order of 500 to $800 \mathrm{r}$ weekly are given for 2 to 4 weeks, and operation is advised 10 to 14 days after the last treatment. Pre-operative radiation can be followed by post-operative treatment in the more heavily vascularized cases.

For vernal catarrh, the patient should ideally be treated one month before the expected onset of the attack. A lead shield is placed in the conjunctival sac to protect the eye and the size of field used will depend on whether one or both lids are to be treated, in each case the fornices must be irradiated and the field extended to the bony orbital margin. A dose of $100 \mathrm{r}$ is given once weekly for 4 weeks. If the patient is seen during an attack, the same treatment should be given. It is advisable when treating any bilateral eye condition to begin by treating the worse eye first and to treat both eyes only if no exacerbation of symptoms has occurred. For bulbar lesions, beta-radiation should be used in order to avoid lens damage, a dose of $500 \mathrm{r}$ being given once a week for 4 weeks.

Recurrent pterygium can be treated by beta-radiation using the strontium shell, four doses of 500 to $600 \mathrm{r}$ being given at weekly intervals. It can also be treated post-operatively by low-voltage $x$-rays $(60 \mathrm{kV}$.) given through a $2 \times 1-\mathrm{cm}$. field, so placed that its edge is at the apex of the pterygium and tangential to the cornea. The eye is anaesthetized and a lid-retractor is used. A single dose of $600 \mathrm{r}$ is given, and this can be repeated after 6 weeks if necessary.

The doses used in beta-ray therapy bear little relation to the doses employed in low-voltage $x$-ray therapy, for the following reasons:

(i) The marked difference in penetration of the two types of radiation. Under our treatment conditions, the dose of $x$-radiation incident on the anterior surface of the lids falls to half its intensity at a depth of $1 \cdot 1 \mathrm{~cm}$. In contrast, the dose of strontium radiation incident on the surface of the cornea falls to half its intensity at a depth of $1.3 \mathrm{~mm}$.

(ii) The volumes of tissue irradiated by each method vary greatly. With lowvoltage therapy the lids and the eye itself are irradiated, whereas with beta-radiation only tissues in close contact with the source are irradiated. There is an inverse relationship between the volume of tissue irradiated and the size of the dose, i.e. the larger the volume the smaller the dose that can be safely given.

Any attempt to imitate the high single doses used in beta-ray therapy with low-voltage $x$-ray therapy would almost certainly be harmful to the inflamed eye. Conversely, to imitate the small doses used in $x$-ray therapy with a beta-ray source would be pointless and ineffective.

\section{(B) Benign Tumours}

(1) Haemangiomata.-It is our general policy:

(i) not to give large doses of irradiation to these tumours;

(ii) to avoid radon seed or other implantation methods;

(iii) to repeat treatment only once or twice with the longest possible intervals between treatments. 
Gamma-radiation is to be preferred, but, because of the greater ease in protecting the eye, contact therapy $(60 \mathrm{kV}$.) is usually employed for lid angiomata, and the child is anaesthetized for the treatment in most cases. A single dose of $250-400 \mathrm{r}$ is given, depending on the age of the patient and the thickness of the lesion, the lower dose never being exceeded in a newborn infant. The treatment is not repeated as long as regression continues, but if the improvement is not maintained a further treatment is given after 6 months, and very rarely a third treatment after 18 months. The child should be treated as soon after birth as possible and the parents warned that complete regression may not be obtained for from 3 to 5 years or more (Fig. 12).

(2) Papillomata. - $X$-ray therapy is used for a solitary papilloma, a single dose of $2,000 \mathrm{r}$ at $60 \mathrm{kV}$. being given. Infective or multiple papillomata in children are treated by $x$-ray therapy to the lid lesions, a single dose of $600 \mathrm{r}$ being given, and beta-ray therapy to any bulbar conjunctival lesion, a single dose of $1,000 \mathrm{r}$ being given. These doses can be repeated at the end of 3 months if necessary.

(3) Keratoses.-The technique is the same as for solitary papilloma.

(4) Keloids. - A single dose of $600 \mathrm{r}$, using $x$-rays at $60 \mathrm{kV}$. or $100 \mathrm{kV}$., is given to the scar and treatment is repeated in 3 months if necessary.

\section{COMPLICATIONS OF RADIOTHERAPY}

Complications should not be encountered in the radiation treatment of inflammatory processes.

(1) Exacerbation of symptoms during radiotherapy is nearly always a sign of improper dosage; in using $x$-ray therapy, the minute doses given never provoke exacerbations such as may occur with higher doses.

(2) Infection and traumatic damage to the eye may occur when using beta-rays, but with proper care these complications are entirely avoidable. Merriam (1956) has reported on the occurrence of radiation cataract after strontium beta-radiation. He notes that damage to the lens can occur only with very high surface doses. There are no indications for very high beta-ray dosage, i.e. over 4,000 to $5,000 \mathrm{r}$, in the treatment of non-neoplastic disease, and to date we have no record of a radiation cataract produced by beta-rays.

(3) Radionecrosis has occurred only after the single-dose method of treating lid tumours. A fractionated dose method is clearly preferable if radiotherapy is to be used safely rather than economically.

\section{SUMMARY}

In assessing the value of radiotherapy in the treatment of non-malignant disease, it is important to remember the following facts:

(1) Radiotherapy is not a specific remedy.

(2) Many of the lesions treated are normally capable of spontaneous healing, but may relapse in a certain unknown proportion of cases. 
(3) Radiation is often used only when all else has failed and patients often come with a chronic long-standing lesion or in an acute " resistant" stage.

(4) Because of the benign or self-limiting nature of many of the conditions treated, routine follow-up is not undertaken. A detailed statistical analysis of results, such as is available in the treatment of malignant diseases, is scarcely indicated.

Tables II to VIII show the results of treatment obtained at the Royal Marsden Hospital in a series of cases of various kinds.

TABLE II

HAEMANGIOMATA AND PAPILLOMATA

\begin{tabular}{|c|c|c|c|c|c|}
\hline \multirow{2}{*}{\multicolumn{2}{|c|}{ Condition }} & \multirow{3}{*}{$\begin{array}{c}\text { Seen } \\
50\end{array}$} & \multicolumn{2}{|c|}{ Treated } & \multirow{3}{*}{$\begin{array}{c}\text { Not Treated } \\
3\end{array}$} \\
\hline & & & Improved & Failed & \\
\hline \multirow{2}{*}{ Haemangiomata ... } & Lids & & 45 & 2 & \\
\hline & Canthi & 7 & 4 & - & 3 \\
\hline Papillomata & Lids & 41 & 27 & 3 & 11 \\
\hline
\end{tabular}

TABLE III

VERNAL CATARRH

\begin{tabular}{c|c|c|c}
\hline \multirow{2}{*}{ Seen } & \multicolumn{2}{|c|}{ Treated } & \multirow{2}{*}{ Not Treated } \\
\cline { 2 - 4 } & Improved & Failed & \\
\hline 21 & 15 & 2 & 4 \\
\hline
\end{tabular}

TABLE IV

VIRUS INFECTIONS OF THE OUTER EYE

\begin{tabular}{|c|c|c|c|c|c|c|c|c|}
\hline \multirow{2}{*}{\multicolumn{4}{|c|}{ Infection }} & \multirow{3}{*}{$\begin{array}{c}\text { Seen } \\
22\end{array}$} & \multicolumn{3}{|c|}{ Treated } & \multirow{3}{*}{$\begin{array}{c}\begin{array}{c}\text { Not } \\
\text { Treated }\end{array} \\
2\end{array}$} \\
\hline & & & & & \multirow{2}{*}{$\frac{\text { Relieved }}{3}$} & \multirow{2}{*}{$\frac{\text { Improved }}{10}$} & \multirow{2}{*}{$\frac{\text { Failed }}{7}$} & \\
\hline Dendritic ulcer & ... & $\cdots$ & $\ldots$ & & & & & \\
\hline Disciform keratitis & $\cdots$ & $\ldots$ & $\ldots$ & 17 & 3 & 7 & 6 & 1 \\
\hline Post-herpetic pain & ... & ... & $\ldots$ & 11 & 2 & 3 & 6 & 0 \\
\hline Superficial punctat & e ke & & $\ldots$ & 73 & 12 & 44 & 12 & 5 \\
\hline
\end{tabular}

By courtesy of the Editors of the Transactions of the Ophthalmological Society of the United Kingdom.

TABLE V

ROSACEA KERATITIS

\begin{tabular}{c|c|c|c}
\hline Treated & Healed & Improved & $\begin{array}{c}\text { Failed or } \\
\text { too Recent }\end{array}$ \\
\hline 101 & 25 & 68 & 8 \\
\hline
\end{tabular}


TABLE VI

MOOREN'S ULCER

\begin{tabular}{|c|c|c|c|c|c|}
\hline \multicolumn{3}{|c|}{ Treated } & \multirow{2}{*}{$\begin{array}{c}\text { Healed } \\
11\end{array}$} & \multirow{2}{*}{$\frac{\text { Improved }}{10}$} & \multirow{2}{*}{$\frac{\begin{array}{c}\text { Failed or } \\
\text { too Recent }\end{array}}{13}$} \\
\hline Patients & $\ldots$ & 34 & & & \\
\hline Eyes $\ldots$ & $\ldots$ & 45 & 15 & 14 & 16 \\
\hline
\end{tabular}

TABLE VII

PTERYGIA

\begin{tabular}{|c|c|c|c|c|c|c|}
\hline \multirow{2}{*}{\multicolumn{3}{|c|}{ Seen }} & \multicolumn{3}{|c|}{ Treated } & \multirow{3}{*}{$\begin{array}{c}\text { Not Treated } \\
6\end{array}$} \\
\hline & & & \multirow{2}{*}{$\begin{array}{c}\text { Successful } \\
3\end{array}$} & \multirow{2}{*}{$\begin{array}{c}\text { Improved } \\
7\end{array}$} & \multirow{2}{*}{$\begin{array}{c}\text { Failed } \\
3\end{array}$} & \\
\hline $\begin{array}{l}\text { Patients } \\
\text { Eyes }\end{array}$ & $\begin{array}{l}\ldots \\
\ldots\end{array}$ & $\begin{array}{l}12 \\
19\end{array}$ & & & & \\
\hline
\end{tabular}

TABLE VIII

CORNEAL GRAFTS

\begin{tabular}{|c|c|c|c|c|c|c|c|c|}
\hline \multirow{2}{*}{$\begin{array}{l}\text { Radiation } \\
\text { Treatment }\end{array}$} & \multicolumn{2}{|c|}{ Number Seen } & \multicolumn{2}{|c|}{ Satisfactory } & \multicolumn{2}{|c|}{ Failed } & \multicolumn{2}{|c|}{ Indeterminate } \\
\hline & Patients & Eyes & Patients & Eyes & Patients & Eyes & Patients & Eyes \\
\hline $\begin{array}{c}\text { Post-keratoplasty } \\
\text { Lamellar } \quad . . . \\
\text { Full-thickness... }\end{array}$ & 67 & $\begin{array}{l}70 \\
26 \\
44\end{array}$ & 21 & $\begin{array}{c}22 \\
1\end{array}$ & 22 & 23 & 24 & 25 \\
\hline Pre-keratoplasty... & 18 & 19 & 2 & 2 & 10 & 10 & 6 & 7 \\
\hline $\begin{array}{l}\text { Pre- and Post- } \\
\text { keratoplasty }\end{array}$ & 5 & 7 & 2 & 2 & 2 & 3 & 1 & 2 \\
\hline Total $\ldots$ & 90 & 96 & 25 & 26 & 34 & 36 & 31 & 34 \\
\hline
\end{tabular}

I am indebted to the members of the staff of the Moorfields, Westminster and Central Eye Hospital and of the Royal Eye Hospital for sending most of the cases, and for their co-operation in treatment. I am grateful to the Editor of the British Journal of Radiology for permission to reproduce Figs 1, 3, 4, 18, and 19, and to the Editor of the Transactions of the Ophthalmological Society of the United Kingdom for permission to publish Table IV.

\section{REFERENCES}

Pohre, E., ed. (1950). “Clinical Radiation Therapy", 2nd ed. Lea and Febiger, Philadelphia. LEDERMAN, M. (1956a). Brit. J. Radiol., 29, 1.

- (1956b). Trans. ophthal. Soc. U.K., 76. (In the Press.)

MERRIAM, G. R. (1956). Radiology, 66, 240. 